\title{
M.B.I.G., de José Martret. Teatro posmoderno contra el capitalismo posmoderno
}

\section{José Martret's M.B.I.G. Postmodern Theatre vs. Postmodern Capitalism}

\author{
Guillermo Laín Corona \\ Universidad Nacional de Educación a Distancia (UNED) \\ glaincorona@flog.uned.es \\ ORCID iD: https://orcid.org/0000-0003-4125-0834
}

\section{RESUMEN}

José Martret (Palma de Mallorca, 1971) utiliza Macbeth como base para hacer una obra de teatro propia: M.B.I.G. (estrenada el 20 de noviembre de 2013 y publicada en 2014). Con un formato inmersivo, una estructura metateatral y una estética posmoderna de tintes fandom y relacionada con productos culturales de masas, como la serie de televisión Mad Men (2007-2015), M.B.I.G. resemantiza el texto original de Shakespeare para hacer un feroz ataque contra las sociedades capitalistas actuales.

Palabras Clave: Teatro español actual; José Martret; M.B.I.G.; Shakespeare; Macbeth.

\section{ABSTRACT}

José Martret (Palma de Mallorca, 1971) uses Macbeth as a tool for his own play M.B.I.G. (premiered on November 20th 2013, published in 2014). With an inmersive format, a metatheatrical structure and a postmodern aesthetic linked to fandom and products of mass culture, such as the TV series Mad Men (2007-2015), M.B.I.G. re-semanticises Shakespeare's original text and offers a violent attack on contemporary capitalist societies.

Key words: Current Spanish Theatre; José Martret; M.B.I.G.; Shakespeare; Macbeth. 
A falta todavía de perspectiva histórica suficiente, se hace cada vez más evidente que, conforme ha ido avanzado el siglo XXI, las renovaciones teatrales se han basado en buena medida en «El teatro fuera del teatro», por tomar el título del número 7 de la revista Don Galán, dedicado monográficamente a la cuestión ${ }^{1}$. Esta tendencia engloba formatos como el site-specific theatre, estudiado extensamente por Pearson (2010), y el teatro inmersivo, del que habla White (2012). Por ejemplo, Erin Mee en 2014 concibió la pieza Pool Play en una piscina ${ }^{2}$, de modo que actores y público, en bañador, se sumergían literalmente en el espacio de representación, lográndose, con ello, un efecto de inmersión en los hechos de la historia representada. Por supuesto, estas innovaciones no surgen de la nada. Como explica la propia Mee: «Most theatre in the Middle Ages was site-specific, immersive and participatory, but there's a resurgence now» (Cfr. Mandell 2015). Y tampoco este resurgimiento mencionado es tan actual como parece. En España, La Fura dels Baus lleva desde 1979 aprovechando fábricas y espacios similares, por los que hace transitar al público a lo largo de la representación, como ocurría en Tier Mon (1988) ${ }^{3}$.

En los últimos años, este tipo de teatro se viene produciendo en España por los cauces alternativos de lo que desde hace algunos años y hasta recientemente se ha llamado teatro off. Esto implica que con frecuencia se trata de iniciativas que se desarrollan con medios económicos precarios y/o en circuitos reducidos, aunque a veces se logra el éxito empresarial, de público y de crítica. Ahí está el caso Microteatro por Dinero, una propuesta de piezas breves (quince minutos) con efecto inmersivo, porque se representan en salas minúsculas en las que el público prácticamente está encima de los actores, $\mathrm{y}$, en cierto modo, de tipo site-specific, porque las salas forman parte de las instalaciones de un bar. Seguramente, en su origen, la idea del Microteatro buscaba hacer de la necesidad virtud: reducir costes en espacio y tiempo y aumentar beneficios mediante la venta de consumiciones. En todo caso, lo que empezó como una iniciativa modesta se ha convertido en un negocio exitoso, que tiene sedes en Miami y varias capitales de América Latina y que pone en escena textos escritos, dirigidos y/o representados por celebridades de la literatura, el teatro y el cine (Nimo 2015).

1 Véase: http://teatro.es/contenidos/donGalan/donGalanNum7/index.php (consulta: 0504-2018).

2 Véase la web de la compañía: https://www.thisisnotatheatrecompany.com/currentproduction (consulta: 20-01-2017).

${ }^{3}$ Véase su página web: http://www.lafura.com/obras/tier-mon/ (consulta: 13-01-2017).

${ }^{4}$ El Microteatro viene a actualizar una larga tradición de teatro breve, que en España tiene referentes tan destacados como los entremeses áureos o el teatro por horas del siglo XIX y que a comienzos del XXI está muy activa (Romera Castillo, ed. 2011). En la actualidad, hay otros formatos parecidos al de Microteatro, como el teatro en serie, y ejemplos similares «en otros países de habla hispana -como el teatro de cerca, del que la casa-teatro argentina Timbre 4, de Claudio Tolcalchir, es una recurrente referencia-», según ha estudiado López de Arriba Escribano (2017). 
Como parte de esta tendencia renovadora, el trabajo teatral de José Martret (Palma de Mallorca, 1971) ha sido tal vez uno de los exponentes más sobresalientes del off en Madrid, hasta el punto de que José Luis Romo (2016), en una reseña para El Mundo, hablaba de un «modelo revolucionario». Su obra ya ha merecido la atención de la crítica académica (Ruiz Lluch 2017). En particular, Martret ha desarrollado una forma de site-specific theatre según la cual se crea un espacio pensado y decorado para una obra determinada, de modo que ese espacio se cierra cuando dicha obra deja de representarse. Con estas premisas, José Martret y Alberto Puraenvidia (escenógrafo y director artístico), crearon, primero, La Casa de la Portera, en una vivienda de C/ Abades, 24 (Madrid), para la cual se concibió Ivan-OFF (estrenada el 8 de marzo de 2012), a partir del Ivanov de Chejov (con un juego de palabras en el título que da cuenta, por cierto, de su voluntad de ser parte del teatro off). Una vez acabó este espectáculo, el espacio cerró el 23 de junio de 2015. En la estela del éxito obtenido, crearon luego, en un piso de C/ Huertas, 48, también en Madrid, La Pensión de las Pulgas, concebida para representar M.B.I.G. (McBeth International Group). Esta obra y su espacio se estrenaron el 20 de noviembre de 2013 y la última función y clausura tuvo lugar el 24 de julio de 2016.

Según he estudiado en otro trabajo (Laín Corona 2017, 252-255), este proyecto de Martret tiene que ver con el teatro inmersivo, por varias razones que se resumen aquí. Como ilustra La Casa de la Portera (Figs. 1 y 2) , $^{5}$ la vivienda elegida para la representación es sometida a un proceso de decoración de deslumbrante estética, que casi la convierte en un objeto artístico en sí. Lo mismo ocurre en La Pensión de las Pulgas, de la que se ofrecen imágenes más adelante.

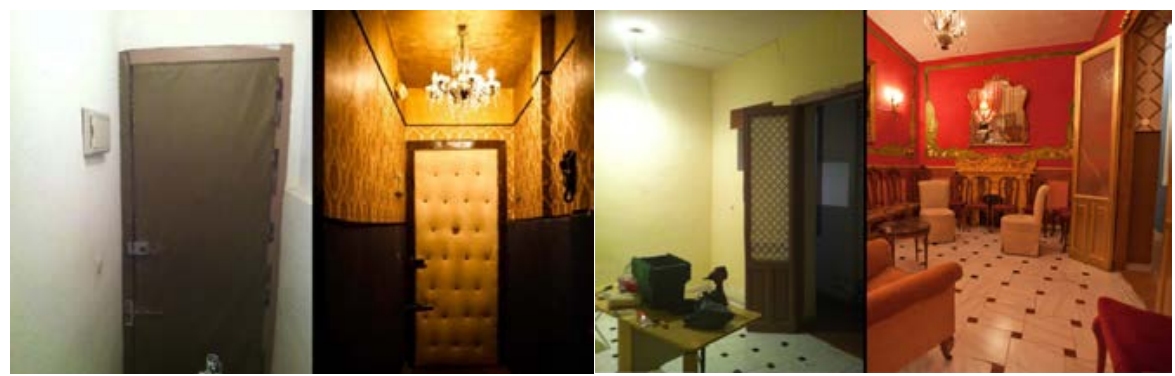

Figura 1. La Casa de la Portera. Restauración de la puerta de entrada
Figura 2. La Casa de la Portera. Restauración del salón rojo

Gracias a este cuidadoso tratamiento del espacio y el decorado, se crea la ilusión de que el espectador no entra en un recinto teatral en el que se repre-

5 Todas las imágenes de La Casa de la Portera y La Pensión de las Pulgas incluidas en este artículo están tomadas de https://lacasadelaportera.com/acerca-de/ (consulta: 13-01-2017). 
senta una obra, sino en el espacio real del mundo real de la historia, en lo cual se basa el efecto inmersivo. Además, a ello contribuyen otros factores. El público transita por diferentes estancias; en cada una de ellas, se sienta en sillas que perimetran las paredes y los actores trabajan en el centro. Se derrumba, así, la cuarta pared, que separa el escenario de la sala y al actor del espectador, especialmente considerando las reducidas dimensiones del espacio, a la manera del Microteatro. En efecto, las estancias eran tan pequeñas, que en cada función solo se podía dar cabida a un grupo reducido de espectadores: 25 (La Casa de la Portera) y 35 (La Pensión de las Pulgas).

En el caso concreto de M.B.I.G., es igualmente importante para el efecto inmersivo la estructura metateatral (Laín Corona 2017, 261-264). En La Pensión de las Pulgas, se crea la ilusión de que los espectadores acuden a las oficinas de una empresa real de los años 60, en calidad de invitados para contemplar su funcionamiento y razones de su éxito. Para ello, Martret se vale del personaje de Camelia, que es secretaria en dicha empresa y, como tal, asume el papel de guía durante la visita. Camelia se dirige al público en varios monólogos para explicar las peculiaridades de la vida empresarial y, entre monólogos, se contempla lo que pasa concretamente en esta empresa. Ahora bien, lo que pasa es Macbeth de Shakespeare. O sea, la obra de teatro de Macbeth se representa dentro de la obra de teatro de la visita del público a la empresa. De esta manera, la obra de Shakespeare adquiere un nuevo significado.

Es un fenómeno frecuente y normal en arte y literatura que las obras se interpreten de manera distinta según las épocas. Sin ir más lejos, en 1999 Norman Augustine y Kenneth Adelman publicaron un libro en el que daban una interpretación particular de las obras de Shakespeare como consejos sobre cómo gestionar eficazmente una empresa, o sea: Shakespeare en la empresa. Reconociendo que no se trataba de un estudio académico, Augustine y Adelman (2000, 21-22) lo que pretendían era «encontrar analogías útiles» en las obras de Shakespeare como «lecciones de gestión empresarial».

Ahora bien, a diferencia del ensayo de Augustine y Adelman, M.B.I.G. no es meramente una actualización o interpretación del sentido de Macbeth. Ni tan siquiera es una adaptación teatral de Macbeth, como en principio pudiera parecer, considerando que esta pieza se representa casi íntegra dentro de M.B.I.G. En clave de análisis semiótico y con las teorías de Genette, se puede argumentar (Laín Corona 2017, 255-261) que, aun partiendo de Macbeth, M.B.I.G. es una obra nueva. La idea es que Macbeth, traspuesta en el marco metateatral e inmersivo, sin perder su sentido original, adquiere un sentido nuevo, pero complementario, del que resulta M.B.I.G. como obra autónoma. Además, a diferencia también de Shakespeare en la empresa, que ofrece una visión complaciente del mundo de los negocios, M.B.I.G. es un duro ataque contra las sociedades capitalistas, en relación con la posmodernidad. Esto es lo que voy a estudiar aquí, como complemento a mi artículo anterior sobre la estructura metateatral e inmersiva de M.B.I.G. 


\section{POSTEATRO Y POSMODERNIDAD EN M.B.I.G.}

En su libro sobre Postdramatisches Theater, Hans-Thies Lehmann (2006) define el teatro posdramático como aquel que se libra de la autarquía del texto, reduciendo al mínimo la dimensión literaria y potenciando la experiencia como espectáculo. El teatro posdramático, según Lehmann, se desarrolla a partir de los años 60, con autores como Robert Wilson, Heiner Müller o Tadeusz Kantor, en paralelo con las formas de arte posmodernistas, y llega a la actualidad. Dada la falta de espacio para abordar una cuestión tan compleja, no cabe entrar en disquisiciones sobre las diferencias entre posmodernismo, como movimiento estético, y posmodernidad, como actitud de banalidad o De la ligereza en las sociedades occidentales, por tomar el título de uno de los últimos libros de Gilles Lipovetsky (2016). Baste señalar que el teatro posdramático, que, como forma artística, parte del posmodernismo, permite ser analizado también a la luz de la posmodernidad. Y que la inmersividad puede considerarse una nueva vuelta de tuerca en el teatro posdramático.

La compañía británica Punchdrunk (fundada en 2000) montó The Drowned Man: A Hollywood Fable (2013) en los antiguos almacenes de la Royal Mail en el londinense barrio de Paddington, como una explosión de teatro inmersivo. La historia se contaba prácticamente solo con coreografía, danza y un decorado inmenso de unos 18.000 metros cuadrados, por los cuales el público debía desplazarse, mezclándose con los actores, pero distinguiéndose de ellos por el uso de unas máscaras con grandes ojos que provocaban una clara sensación voyeurista ${ }^{6}$. La inmersividad de este espectáculo está en línea con el teatro posdramático como experiencia en sí, libre del texto (posmodernismo). A la vez, se basa en una exaltación de aspectos propios de la posmodernidad. Un rasgo de la banalidad o ligereza posmoderna es, paradójicamente, el formato gigante de sus productos, entre ellos, los del arte: «De cara a una sociedad hipermediática, saturada de estímulos visuales, no deja de aumentar el número de obras que tratan de imponerse por su impacto visual, por una monumentalidad que produce una fuerte impresión inmediata» y que se basan en proporcionar «experiencias sensoriales y emocionales» (Lipovetsky 2016, 225). Y ello en el marco de la sociedad de consumo de masas. Hay que considerar que The Drowned Man, siquiera fuera por el inmenso espacio, era un producto de costosa inversión, pero tremendamente rentable, ya que daba acceso a cientos de personas al día.

M.B.I.G., de José Martret, permite un análisis parecido. Es cierto que se trata de un espectáculo de dimensiones reducidas y que, como proyecto off, no llega al público de masas. Además, el nivel textual tiene mucha importancia en este caso, por el uso de un clásico de la literatura como Shakespeare. Sin embargo, hay que

${ }^{6}$ Véase su página web: https://www.punchdrunk.org.uk/the-drowned-man/ (consulta: 13-01-2017). 
tener en cuenta varias cosas. A pesar de sus pequeñas dimensiones, M.B.I.G. fue una iniciativa ambiciosa, con una inversión económica en los decorados, si no desmesurada, sí mucho más importante que otros proyectos off, logrando estar en cartel durante más tiempo y, por tanto, llegando a más público. Y, gracias a la estructura metateatral, la dimensión textual asociada a Macbeth es secundaria con respecto a la visita a la empresa y al tratamiento artístico del espacio, por lo que prevalece la experiencia audiovisual (Laín Corona 2017, 262) sobre el texto de Shakespeare. Así, M.B.I.G. tiene mucho que ver con el teatro posdramático.

Asimismo, la elección de Macbeth como base de M.B.I.G. puede que no sea casual, en el marco de la sociedad posmoderna. M.B.I.G. se representó entre 2013 y 2016, o sea, en torno al cuarto centenario de la muerte de Shakespeare. Dado que se estrenó tres años antes del centenario, es posible que Martret no lo hiciera por esta razón, pero el dato, al menos, fue seguramente relevante para determinar la prolongación de la representación hasta 2016, el año mismo del centenario, y muchos espectadores probablemente lo tenían en mente al asistir. Considérese que Macbeth «llegó a convertirse en favorita del público» ya en 1660 (Portillo 2007, 174); desde entonces, a pesar de algún altibajo y a pesar de (o gracias a) adaptaciones de diferente tipo, la historia escénica de Macbeth está marcada por el éxito, siendo, en un recuento de 1987, «la tercera [obra] en número de veces traducida y editada en nuestro país» (Conejero Dionís-Bayer 2015, 34). Macbeth, por tanto, siendo un clásico indiscutible, se ha convertido también en un producto cultural de masas. Y, entre las diferentes adaptaciones, pervive en la actualidad en formatos posmodernos, como el de la cultura fandom, que estudian Lozano y Hermida (2007).

Fandom (de inglés fan kingdom, 'reino del fan') es un término que se aplica a un grupo de admiradores fanáticos (fans) de una actividad, un famoso, una moda o, en general, cualquier forma de cultura de masas, aunque suele aplicarse a la ciencia ficción y la fantasía, como los superhéroes. El fandom se caracteriza, entre otras cosas, por: (i) un fuerte sentimiento de identificación grupal a raíz de y en torno al objeto cultural admirado (de ahí la importancia actual de las redes sociales en Internet, como canal de expresión del sentimiento colectivo), así como (ii) el desarrollo de diferentes tributos y subproductos derivados para consumo de los grupos de fans, como convenciones de cosplay (del inglés, costum play, 'juego de disfraces'), fanzines (del inglés fan's magazine, 'revista del fan') y, recientemente, memes y gifs. También se relacionan con el fandom los videojuegos, grupos musicales y series de televisión.

Este es un modo ciertamente superficial de adaptación de Macbeth, reducida a un meme o un disfraz de, por ejemplo, Halloween. Sin embargo, si no fandom en sentido estricto, sí tienen mucho de estética posmoderna algunas adaptaciones recientes de Macbeth, como la que, precisamente, ha realizado Punchdrunk en Nueva York, en cartel desde 2011. Sleep No More es una adaptación de Macbeth en for-

\footnotetext{
7 Véase la página web de la obra: http://www.sleepnomore.com/ (consulta: 20-01-2017).
} 
mato inmersivo, que ha generado entre el público una fiebre fanática, como informan, precisamente, fuentes de formato típico del fandom, como los blogs ${ }^{8}$. Asimismo, Sleep no More dialoga de manera en cierto modo pastiche con la cultura de masas, a través del cine de Alfred Hitchcock y Stanley Kubrick (Aguilar 2012).

El pastiche es una categoría escurridiza y normalmente se percibe como un rasgo posmoderno negativo: «canibalización aleatoria de todos los estilos del pasado», fruto de la desaparición de lo personal, de la búsqueda de lo nuevo y de la imposición de la globalización, o sea, mezcla de «voces almacenadas en el museo imaginario de la cultura global» (Jameson 1996, 37-38). Ahora bien, el pastiche, como estrategia posmoderna, también ofrece frutos excelentes y no es solamente batiburrillo superficial de estilos del pasado. Ahí está el fenómeno de las series de televisión más recientes, como Penny Dreadful (2014-2016), de John Logan, que mezcla los mundos ficticios de Drácula, Frankenstein y Dorian Grey. Resulta oportuno también citar House of Cards (2013-2017), de Beau Willimon, ya que tiene lazos con Macbeth, según se hace notar en The Huffington Post ${ }^{9}$. Se puede estudiar M.B.I.G. desde esta perspectiva.

Tomando la teoría de Jameson, M.B.I.G. es pastiche porque recupera, no solo un pasado, sino varios: el medieval de Macbeth, el victoriano de la época de Shakespeare y el de los años 60 de la empresa ficticia. Además, si recupera esos años, lo hace como respuesta a la moda vintage, según se puede ver en el despacho presidencial de La Pensión de las Pulgas (Fig. 3). Se usa aquí el término vintage sin ánimo de pretensión técnica, sino solo para ilustrar grosso modo un tipo de estética retro, que es un rasgo típicamente posmoderno: la «conversión del arte en moda» (Lipovetsky 2016, 205-226).

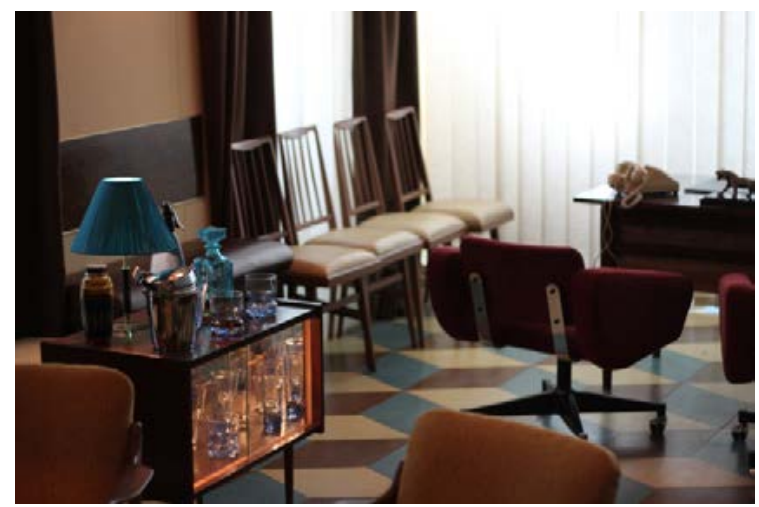

Figura 3. Detalle del despacho presidencial de M.B.I.G. en La Pensión de las Pulgas

\footnotetext{
${ }^{8}$ Véase, por ejemplo: http://annasilman.tumblr.com/snm (consulta: 26-09-2017).

9 «9 Things 'House Of Cards' Took From Shakespeare», The Huffington Post [EE.UU.], 24-02-2014.http://www.huffingtonpost.com/2014/02/21/house-of-cards-shakespeare-_n_4823200. html (consulta: 17-01-2017).
} 
En la primera acotación de M.B.I.G., se dice que Camelia: «Va vestida como en los años 60, lleva un vestido ajustado que resalta todas sus curvas y que cubre sus rodillas. Es una mujer atractiva, sensual y muy inteligente» (Martret 2014, 17) ${ }^{10}$. No es solo que la acotación hable de recrear la estética de los 60, sino que puede intuirse una relación con otra serie de televisión: Mad Men (2007-2015), de Matthew Weiner. Aquí se narra la historia de varios personajes ligados al mundo empresarial de la publicidad en torno, precisamente, a los 60. Como Camelia en M.B.I.G., Joan Holloway en Mad Men también es secretaria y también tiene un look de curvas marcadas, sensualidad y vestido que le cubre las rodillas. Así puede verse en la figura 4, en la que, además, se percibe un decorado de oficina similar al despacho presidencial de La Pensión de las Pulgas (Fig. 3); por ejemplo, el parecido en la gama de colores (azules, marrones, granates y ocres).

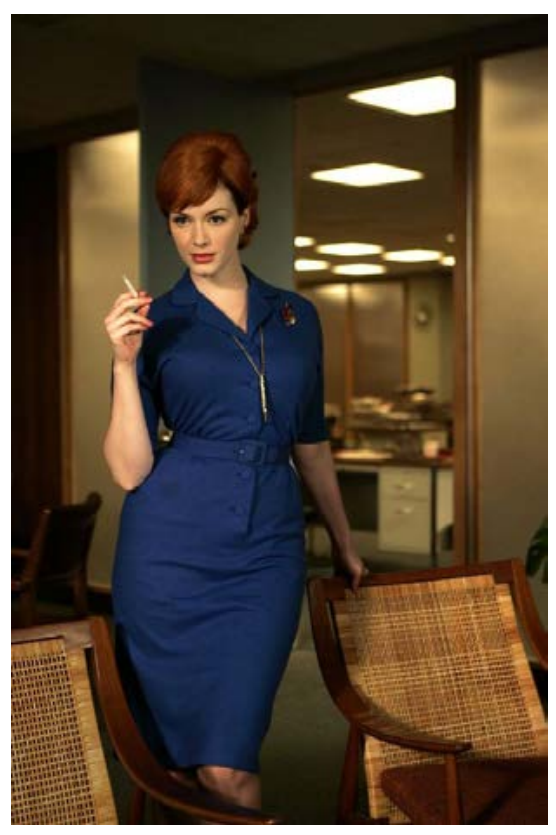

Figura 4. Joan Holloway en Mad Men

El uso de elementos estéticos propios de la posmodernidad, como el pastiche, con sus connotaciones negativas, puede llevar a suponer que estos produc-

${ }^{10}$ En adelante, se citará esta obra siempre a través de esta edición, pero, dado el gran número de citas y para mayor claridad, en vez del sistema autor/fecha, se indicará el título abreviado, acto y escena, en números romanos, y, en su caso, página(s), en números arábigos. Aquí, M.B.I.G., I.i, 17. 
tos culturales son insustanciales, como lo es un amplio espectro del fandom. Muchos pensadores de la posmodernidad, como Zygmunt Bauman (2003) en su libro ya seminal sobre la Modernidad líquida, proceden del marxismo, y sus críticas suelen argüir que la cultura posmoderna es el resultado del capitalismo posindustrial: un producto de consumo para un individuo hipernarcisista que solo busca la diversión banal (La era del vacio, otro título de Gilles Lipovetsky). Ahora bien, un producto posmoderno puede contener sentidos profundos y críticos. Mad Men es, en efecto, un pastiche sesentero, pero critica con calidad artística la publicidad y el consumismo: «the exact status of the series as an endorsement or critique of consumerism» (Booker y Batchelor 2016, 78). Lo mismo ocurre con M.B.I.G. Martret rescata el pasado y mezcla estéticas, de Macbeth a los años 60, en un formato doblemente pastiche, porque a su vez se basa en Mad Men. Sin embargo, arremete de manera muy inteligente contra uno de los grandes problemas de la posmodernidad: la organización de la vida laboral y empresarial de la sociedad posindustrial. En esto se basa el proceso de resemantización de Macbeth en M.B.I.G.

\section{ReSEMANTIZACión POSMODERnA DE MACBETH EN M.B.I.G.}

El elemento más importante para conseguir la resemantización de Macbeth son las intervenciones de Camelia, personaje añadido en M.B.I.G. por Martret para tal fin. Como se apuntó más arriba, la representación de Macbeth transcurre entre los monólogos de ella con el público, creándose la ilusión de que la acción de la obra de Shakespeare es lo que realmente pasa en la empresa. Camelia, con sus palabras, viene a dar por cierta esta ilusión, cuando, nada más empezar la obra, le dice al público:

\footnotetext{
Hoy van a tener la oportunidad de descubrir de primera mano cómo es nuestro día a día: cómo se preparan y se desarrollan las reuniones del equipo directivo, cómo y por qué se toman las decisiones más importantes, qué estrategias se siguen para favorecer el crecimiento y la unidad [...] En definitiva: van a poder vivir la empresa desde dentro.
}

Camelia no está diciendo que se va a representar Macbeth como símbolo del funcionamiento de una empresa, y ni siquiera la menciona. Para ella, $M a-$ cbeth no existe, por eso invita a entrar en la empresa: «Después de estas pequeñas pinceladas vamos a entrar en el despacho de nuestro presidente» (M.B.I.G., I.i, 17-18). El presidente, por supuesto, es el rey Duncan, pero Camelia da por sentado que Duncan es el presidente de la empresa M.B.I.G. Por cierto, no es casual que se elija el término de presidente. Entre las opciones posibles, como director general o, en la jerga actual, $C E O$, el título de presidente se opone categóricamente en el imaginario colectivo al de rey, lo cual 
permite sugerir que el Duncan ejecutivo de M.B.I.G. es diferente del Duncan noble de Macbeth. En los monólogos de Camelia, por tanto, todo está pergeñado para que se acepte que Macbeth no es la obra de Shakespeare, sino lo que pasa en la empresa.

Esta identificación repercute en la resemantización de Macbeth, porque permite ser interpretada como el funcionamiento de una empresa. Además, está el refuerzo de una serie de paralelismos entre la obra de Shakespeare y las palabras de Camelia. Para empezar, a pesar de estar enfrentados, hay un paralelismo entre los roles de presidente y rey, por ser ambas las figuras de máximo poder en las organizaciones de Estado que cada uno representa. En particular, explica Camelia que la empresa «no distribuye el poder de forma igualitaria. Nuestro Presidente, y miembro fundador, es el socio mayoritario. Está demostrado que un socio mayoritario o 'socio absoluto' facilita la gestión de la empresa y reduce el impacto de eventuales problemas entre los socios» (M.B.I.G., I.i, 19). Aun sin mencionar Macbeth, Camelia establece un paralelismo entre el mundo monárquico que, simplificando mucho, esta obra representa y el funcionamiento de la empresa en M.B.I.G: el reparto desigual del poder y el presidente como socio absoluto, en referencia a las monarquías absolutas del Antiguo Régimen.

Por su parte, en el discurso de Camelia hay reflexiones sobre el mundo empresarial aplicables a la acción de Macbeth. Ella habla de la importancia del «capital humano», que hace basar en la «cuidadosa selección» de socios; para ello, «se tiene muy presente el indicador de formación, experiencia, edad y motivación» (M.B.I.G., I.i, 18). Más adelante, ya empezada la representación del texto de Shakespeare, el rey Duncan le dice a Macbeth: «Ojalá fueran más pequeños tus méritos, ya te habría dado la justa medida de recompensa y gratitud. Pero no, te debo mucho más de lo que nunca te podré pagar» (M.B.I.G., I.v, 34). A tenor de lo dicho por Camelia, se puede entender aquí que los méritos de Macbeth no son los de soldado y noble, sino los de formación, experiencia, edad y motivación. Así, el diálogo entre Duncan y Macbeth, sin dejar de significar lo que pretendía Shakespeare en origen, se resemantiza como una conversación sobre éxito empresarial.

Además de paralelismos, se producen, por así decir, interferencias entre Macbeth y la visita a la empresa. Para explicarlo, es preciso recordar, primero, que Martret, para incorporar Macbeth dentro de la estructura metateatral, reelabora la obra de Shakespeare. Por un lado, suprime personajes del original e inventa el de Camelia. Por otro, sin embargo, reproduce el texto de Shakespeare prácticamente inalterado (Laín Corona 2017, 256-258). Para ello, redistribuye el texto de los personajes suprimidos entre los incluidos en M.B.I.G. A menudo, este texto es asumido por Camelia, gracias a un paralelismo: al ser secretaria en M.B.I.G., asume el texto de personajes que en Macbeth ejercen de sirvientes, mensajeros, lacayos o similar. En Macbeth, I.v, un mensajero informa a Lady Macbeth de la llegada de su marido a Inverness (Shakespeare 
2015, 98-99 $)^{11}$. Es Camelia quien asume la parte del diálogo que le corresponde a este mensajero (M.B.I.G., II.i, 42). Con esta interferencia de Camelia, se refuerza la ilusión de que Macbeth es lo que pasa en la empresa y se favorece su resemantización empresarial.

Resulta interesante un ejemplo en el que rey Duncan hace entrar a Ross mediante el uso de un interfono y con la asistencia de Camelia en voz en off:

Se enciende una luz en un pequeño aparato que hay sobre la mesa. Duncan aprieta un botón y se escucha la voz de Camelia.

CAmelia en ofF: Ross acaba de llegar. Por la angustia que veo en sus ojos deduzco que trae nuevas noticias, señor (M.B.I.G., I.iii, 24).

Como antes, al asumir el texto de uno de los personajes suprimidos, Camelia interfiere en la obra de Shakespeare, resemantizándola. Y lo hace con un interfono, que remarca más aún la resemantización desde la perspectiva empresarial.

Algo parecido ocurre en otra ocasión, con el refuerzo inmersivo del público como personaje. Camelia habla de un cóctel que involucra a los espectadores: «Ahora están todos ustedes invitados a celebrar con nosotros el gran momento que estamos viviendo en McBeth International Group. Nos espera un cóctel en honor de nuestro nuevo presidente. Síganme, por favor» (M.B.I.G., II.x, 77). Este cóctel es la conocida cena en la que se aparece el espectro de Banquo, que se produce en Macbeth III.iv. En la obra original, los invitados son personajes de relleno interpretados por actores de reparto: caballeros y sirvientes. En la escena correspondiente de Martret, los invitados son los espectadores; de hecho, en la acotación se explica que «Ross y Camelia ayudan a la gente a acomodarse» (M.B.I.G., III.i, 78) y en la función se podía observar que algunos espectadores no se sentaban perimetrando las paredes de la habitación, como era el caso de la mayoría, sino en la propia mesa del convite. Se establece así un nuevo paralelismo: entre los espectadores como invitados a la empresa y como invitados en el banquete de Banquo. Esto, que sirve para reforzar el efecto inmersivo (porque el público tiene una participación doble en la obra, o en dos niveles de ficción), constituye una nueva infiltración del mundo de la empresa en el de Macbeth y, por tanto, repercute en la resemantización.

En esta escena, Camelia es, de nuevo, una pieza clave. Aunque aquí no habla, sí interviene como asistente del rey con diferentes acciones. Es llamativo que se suba a un pódium a "cantar una canción de Rosemary Clooney» (M.B.I.G., III.i, 78-79), una cantante norteamericana de los 50/60. Al tratarse precisamente de los mismos años en que se encuadra la empresa cronológica-

11 También para las citas de Macbeth se usará en adelante el formato de título abreviado, acto y escena, en números romanos, y, en su caso, página(s), en números arábigos. Aquí, Macbeth, I.v, 98-99. 
mente, la canción, como antes el interfono, refuerza la injerencia del mundo empresarial en el de Macbeth y, por tanto, la resemantización. Nótese, por cierto, que se trata de la misma época de $\mathrm{Mad} M e n$, de modo que esta actuación reincide en la naturaleza pastiche de M.B.I.G. Es más, en esta escena aparece un objeto similar al interfono: un teléfono. Para explicarlo, es preciso anotar que en M.B.I.G. se suprime la escena del asesinato de Banquo (Macbeth, III. iii), de modo que los hechos allí relatados se conocen durante el banquete en M.B.I.G., III.i. Esto lo presenta Martret mediante una conversación aparte de Macbeth con los asesinos, a través de un teléfono que, precisamente, trae Camelia en su calidad de sirviente (M.B.I.G., III.i, 79-80).

Junto con los paralelismos e interferencias, también es importante la ironía en el proceso de resemantización de Macbeth en M.B.I.G. La ironía es un recurso característico de Macbeth en su estructuración como tragedia (ironía trágica): «Las profecías que aparecen en I.i son interpretadas por Macbeth de una forma, el desarrollo argumental nos presentará, sin embargo, la contraria» (Conejero Dionís-Bayer 2015, 19). Esto significa que el destino trágico de Macbeth se presenta desde el principio, irónicamente, como promesa de éxito. Ello se basa en la ambigüedad de situaciones y palabras, que Macbeth malinterpreta, mientras que el público asiste consciente del error y, por tanto, horrorizado: «el poder ambiguo y engañoso de las palabras, capaces de significar algo y lo contrario» (Portillo 2007, 183).

M.B.I.G. juega con este mismo recurso. Los discursos de Camelia durante la visita de los invitados pretenden dar una imagen positiva del mundo empresarial, pero los acontecimientos de Macbeth, entendidos como el funcionamiento real de la empresa, lo desmienten. El siguiente ejemplo lo muestra claramente $\mathrm{y}$, además, sirve para completar la interpretación de M.B.I.G. Hasta ahora, se viene señalando que M.B.I.G. transcurre en torno a la visita de unos invitados a una empresa. Sin embargo, la visita no se limita a las instalaciones de la misma, sino a todo lo que rodea la vida empresarial.

Así lo explica Camelia (M.B.I.G., I.vi, 38-39): «Hasta ahora hemos visto al empresario en su lugar de trabajo, pero ¿qué sucede con el resto de su vida?». Para responder a esta pregunta, dice Camelia: «Síganme por favor, porque todos nosotros también hemos sido invitados a Inverness». De este modo, se introduce al público en un problema típico de la sociedad capitalista posmoderna: la conciliación de la vida laboral y la vida personal: «Se ha demostrado que para un empresario, o directivo de una gran empresa, conseguir un entorno familiar óptimo, tranquilo y en el que se pueda relajar, es un factor muy positivo e imprescindible para alcanzar la excelencia». Con estas palabras, Camelia no solo quiere señalar la importancia que ejerce el entorno familiar en una persona dedicada al mundo de la empresa, sino que lo considera clave para el éxito; de hecho, Camelia dice que Inverness es «el hogar en el que reside el triunfador de esta jornada». La ironía de estas palabras se hace evidente por contraste con el funcionamiento real de la em- 
presa, es decir, la representación de Macbeth. Es cierto que Macbeth y Lady Macbeth comparten «un mismo punto de vista y valores», según dice Camelia sobre la importancia de la familia. Pero estos valores se basan en la conjuración y el asesinato, y ello está en las antípodas de lo tranquilo y del espacio para relajarse, que antes Camelia había argumentado como modelo ideal para el éxito empresarial. Desde esta perspectiva, resulta irónico referirse a Macbeth como «triunfador», cuando los acontecimientos lo están guiando inexorablemente al crimen y a la muerte.

Es importante señalar que, conforme avanzan los acontecimientos de Macbeth y se va desvelando el final trágico, Camelia se va asustando. Antes de empezar su último discurso, se señala de ella que: «Su actitud no es la misma que al principio; vemos que está afectada por todo lo que está sucediendo» (M.B.I.G., III.iv, 102). Al principio, si se recuerda, su actitud se describía como «atractiva, sensual y muy inteligente» (M.B.I.G., I.i, 17), lo cual denotaba confianza y provocación. El miedo de ahora, por tanto, reincide en la ilusión de que la acción de Macbeth realmente es lo que pasa en la empresa, porque, si no, Camelia, que es un personaje de ese mundo, no se sentiría afectada. Además, la evolución de su discurso es paralela a la de la trama de Macbeth y se ve sometida al mismo recurso de ironía, basado, a su vez, como se dijo, en la ambigüedad de las palabras. Hablando con miedo, explica Camelia que «Lo que decide si eres parte de esas empresas que sobreviven a los cinco primeros años es [...] Tu capacidad de éxito» (M.B.I.G., III.vi, 102). La ambigüedad de la frase es evidente, porque explicar el éxito o fracaso de una persona en una empresa a partir de su capacidad de éxito puede ser algo positivo (si se interpreta como un incentivo para esforzarse) o negativo (si se toma como una cualidad intrínseca de la persona, de modo que no tener éxito es achacable a una carencia). Por la trayectoria que han venido teniendo los discursos de Camelia, bien puede interpretarse en un sentido positivo, pero el miedo con que habla ahora lo desmiente, irónicamente, como algo negativo. Como se ve, Martret usa las mismas estrategias de la ironía trágica de Macbeth, pero en el marco de resemantización: M.B.I.G. parece que se está describiendo las bondades del mundo empresarial, cuando en realidad lo que pone de manifiesto son las duras condiciones a que se está sometido en ese mundo.

Llegados a este punto, es necesario analizar la naturaleza de Macbeth como tragedia. Según Aristóteles, en su Poética (VI: 1449b), la tragedia es catarsis: «a través de la compasión y el terror lleva a término la expurgación de tales pasiones» (Aristóteles 2002, 45). Esta catarsis se basa en el error o crimen cometido por un personaje. El casamiento de Edipo con su madre es el yerro que provoca el espanto en el espectador, porque atenta contra el orden establecido (incesto), pero es también motivo de compasión, porque es algo involuntario; al final, el momento de arrancarse los ojos es el castigo autoimpuesto que restituye el orden y, por tanto, alivia al espectador del horror. Por supuesto, en 
la tragedia clásica, interviene siempre el poder divino: el combate del héroe contra el poder caprichoso de los dioses.

Según Jan Kott (1967, 17 y 5), «Shakespearian tragedy, unlike ancient tragedies, is not a drama of moral attitudes in face of immortal gods; there is no fate which decides the hero's destiny». Además, no se produce la «essential rule in tragedy in order to produce catharsis». Shakespeare, parafraseando a Kott, presenta una visión pesimista, propia de su época turbulenta, sacudida por la guerra civil, en la que, según la máxima de Hobbes, el hombre es un lobo para el hombre. En esta situación, Shakespeare quiere presentar la existencia de lo que Kott llama el Gran Mecanismo: un aparato sociopolítico, de creación humana, pero que siempre ha existido, que no es propiedad de nadie y que está por encima de todos. Además, es absurdo y acausal, es decir, resulta de la inestabilidad del mundo y no le da respuesta, sino que solo busca seguir existiendo como tal, dentro de su lógica perversa, propia del mundo del que ha nacido: la perpetuación del poder, con la única regla de matar para alcanzarlo o dejarse morir. Este es el carácter inexorable que constituye, según Kott, la tragedia de Shakespeare, sin dioses.

Es verdad que en Macbeth hay unas brujas, que son un elemento sobrenatural, pero no se trata del enfrentamiento del héroe contra los caprichos de los dioses. Las brujas solo verbalizan la lógica inexorable del Gran Mecanismo: el proceso de ascenso al poder. Una vez dentro de este engranaje, Macbeth está condenado a matar para alcanzar el poder y mantenerlo, hasta morir. Pasa a ser señor de Cawdor por las muertes que acomete en la guerra contra el anterior detentor de este título, que es ejecutado. Luego, él mismo mata a Duncan, para ser rey en su lugar, y ordena matar a Banquo, para garantizarse el puesto. Finalmente, muere él en combate con Macduff, y Malcolm se convierte, a su vez, en rey. En la teoría de Kott, este esquema no produce catarsis, porque no hay un castigo ejemplar que ponga fin a la tragedia y, con ello, a la sensación de terror ante los crímenes cometidos. Al contrario, al terminar una tragedia de Shakespeare queda la congoja de que el mecanismo absurdo de poder y muerte se ha de perpetuar eternamente.

Como esta fórmula se basa en una sociedad concreta, marcada por la inestabilidad del periodo isabelino, no es desafortunado extrapolarla a otra época marcada por el malestar sociopolítico, como la posmodernidad actual. Así, en el marco de resemantizaciones que se está analizando y a través de los discursos de Camelia, lo que M.B.I.G. viene a mostrar es la crueldad del capitalismo, como un Gran Mecanismo, ideado por los seres humanos, pero que se escapa al control de estos y dentro del cual están inexorablemente condenados.

Al comenzar la obra, Camelia argumenta lo siguiente: «No les costará entender que un individuo guiado por el objetivo principal de 'mejorar su patrimonio' valorará de forma cuidadosa y exhaustiva la viabilidad del negocio antes de lanzarse al mismo $\mathrm{y}$, una vez iniciado, realizará todos los esfuerzos posibles para consolidarlo» (M.B.I.G. I.i, 20). Términos como individuo, en el 
contexto empresarial que se viene analizando, apuntan a la sociedad liberal-capitalista. La inexorabilidad, que está ligada a toda condena, especialmente en formato trágico, está en el tiempo verbal empleado por Camelia, ya que en español el futuro simple posee diversos sentidos exhortativos que presuponen que se cumpla una acción o comportamiento determinados, como en una orden o en una predicción (RAE, I, 2009: §23.14d, §23.14f y 23.14h), pero también, de manera parecida, en una profecía; además, Camelia usa la expresión tan ilustrativa de hacer todo lo posible. En principio, aquí la inexorabilidad no quiere expresar que estamos condenados al mal, porque todos los aspectos que se presentan son positivos: mejorar, valorar, viabilidad, consolidar, etc. Pero, en el marco de la ironía trágica, esto queda desmentido a lo largo de la obra, de modo que esos esfuerzos posibles son en realidad acciones perversas. Finalmente, lo que queda es la idea de que las acciones para el éxito empresarial son tan malas como las de Macbeth para alcanzar el poder y mantenerlo. No en balde, poco después, cuando Camelia da paso a la acción de Macbeth, presentándola en paralelo a la de la empresa, usa el verbo luchar: «Después de estas pequeñas pinceladas vamos a entrar en el despacho de nuestro presidente. [...] Sus consejeros delegados y su director ejecutivo y de desarrollo se encuentran ahora mismo 'luchando' en esta reunión» (M.B.I.G. I.i, 20). El uso de las comillas en el texto (que, en la actuación, la actriz representaba con un énfasis especial) es una clara muestra del sentido doble y paralelístico que adquiere la palabra: el sentido recto, que se refiere literalmente a la guerra en que participa Macbeth al comienzo de la obra de Shakespeare, y el sentido paralelo de que la acción empresarial es, si no malvada, al menos igual de cruel que esa guerra, o cualquier otra. Luego, Camelia refuerza este doble sentido, al realizar sus explicaciones sobre el ejercicio empresarial mediante símiles relacionados con la guerra y con matar: «¿Cuál es la diferencia entre ser eficiente, ser efectivo y ser eficaz? Una persona eficiente puede matar una mosca de un cañonazo. Será un acto eficaz pero el resultado será desastroso porque para matar esa mosca habremos destruido todo un pueblo» (M.B.I.G., II.x, 74).

No es aleatoria la cuestión de la maldad, ya que es especialmente relevante en Macbeth: «it has the most pronounced atmosphere of evil of any of his plays» y es considerada «his darkest» (Clark y Mason 2015, 1). Se puede resemantizar esta interpretación del mal en M.B.I.G.

Según se viene señalando, la trama de Macbeth se presenta como el funcionamiento real de una empresa, de modo que sus problemas pueden tomarse como los propios del capitalismo; paralelamente, dado el paradigma de maldad de Macbeth, el capitalismo puede tomarse como encarnación del mal. Por supuesto, este análisis solo tiene sentido si, en efecto, Macbeth se ha resemantizado para representar los problemas del capitalismo. De esto han dado cuenta en buena medida ejemplos anteriores, al establecerse paralelismos entre Macbeth y M.B.I.G. Valga uno más, que, además, pone en relación estas reflexiones sobre el capitalismo con las anteriores de posmodernidad. 
En uno de sus discursos, Camelia presenta los «siete hábitos que caracterizan a la gente altamente efectiva» (M.B.I.G., I.x, 74), a partir del libro de Stephen Covey: Los siete hábitos de las personas altamente efectivas (1989). Parafraseando estas teorías, Camelia reivindica «dejar aparte el paradigma de que la victoria de una persona necesariamente entraña la derrota de otro» (M.B.I.G., I.x, 75). La idea pretende transmitir un mensaje positivo, si bien los acontecimientos de Macbeth lo desmienten irremediablemente. Así puede comprobarse a través de un nuevo paralelismo entre la obra de Shakespeare y la dinámica empresarial. El séptimo hábito de Covey para el éxito, descrito por Camelia, es el de «Afilar la sierra». Este principio quiere ser una metáfora del aprendizaje continuo, sin connotaciones negativas: "Hay personas que intentan cortar un árbol sin afilar la sierra porque están muy ocupados cortando el árbol. Si no se apuesta por un aprendizaje continuo, por un progreso renovador, desgastaremos la sierra hasta que la hoja se rompa» (M.B.I.G., I.x, 76). Sin embargo, el mensaje se torna negativo cuando se pone en relación paralela con las palabras que luego pronuncia Malcolm, convenciendo a Macduff para que se levante en armas contra Macbeth: «Afila tu espada con tu dolor. Toda tu tristeza se convierta en rabia y no se ablande tu corazón sino que se llene de ira» (M.B.I.G., III.iii, 101). En la palabra afilar, se superponen, pues, dos sentidos: el positivo de Covey, que habla de aprendizaje para el éxito y que Camelia pretende defender, y el bélico de Macbeth, que es negativo. En aplicación de la ironía trágica, la interpretación que se impone es que, frente a las buenas intenciones de Covey, la realidad del capitalismo posmoderno es que la vida empresarial es una cruenta batalla.

El hecho de usar a Covey refleja que el dardo de Martret se dirige, específicamente, contra el capitalismo posmoderno. Según Lipovetsky (2000, 53-60), la posmodernidad hace uso extensivo de lo psi, esto es, de la psiquiatría, la psicología o derivados sucedáneos, como el yoga, para dar respuesta a los problemas del hiperindividualismo narcisista. Y es que, aislado de los referentes sociales tradicionales (amistades, familia, etc.), el individuo está sometido a altas dosis de angustia vital. Los manuales de autoayuda, que ofrecen formulas presuntamente fáciles y casi milagrosas de felicidad en diferentes ámbitos, son representativos de ello. Esto es lo que representa el libro de Covey. Y, si en él se aborda la eficacia en general, también se han popularizado los manuales de este tipo aplicados al éxito empresarial, que tanto tiene que ver con la trama de M.B.I.G. y según recuerda la propia Camelia: «En los últimos años han proliferado de manera casi escandalosa los cursos sobre gestión de empresa impartidos por grandes gurús que se han hecho multimillonarios» (M.B.I.G., I.vi, 36). Una breve búsqueda en Google permite comprobarlo, con ejemplos como 9 manera de triunfar: el éxito empresarial según sus protagonistas (2000), de Claudio Novo. De hecho, un libro ya citado aquí, a pesar de la mayor enjundia que necesariamente tiene por partir de un análisis de Shakespeare, es una buena muestra de ello, toda vez que Augustine y Adelam ofrecen, de manera parecida a Covey, pero en el ámbito de los negocios, cinco consejos 
para el éxito empresarial: Shakespeare en la empresa. La guía del Bardo de Stratford para liderar y triunfar en el escenario de la empresa.

Como el libro citado en el texto es el de Covey, no se puede determinar si Martret conoció y/o tuvo en mente el de Augustine y Adelam, pero es llamativa la semejanza entre el subtítulo de este y el de M.B.I.G. (McBeth International Group), o La probabilidad del éxito, basada en Macbeth, el clásico de William Shakespeare. Además, no es descabellado suponer que Martret comprendiera el potencial de Macbeth para escribir M.B.I.G. después de leer Shakespeare en la empresa, toda vez que aquí lo que se hace es destacar hasta qué punto se puede extrapolar la producción teatral shakespeariana al mundo de los negocios. Pero, incluso si esto fuera así, está claro que la intención de Martret es completamente diferente, porque, frente a la visión positiva del mundo de los negocios que ofrecen Augustine y Adelman, él ataca duramente ese mundo. Así que el subtítulo de M.B.I.G., si remeda este u otro manual de autoayuda empresarial, lo hace de manera paródica y/o como parte de la estrategia irónica: aparenta presentarse como uno de esos manuales, cuando en realidad es un ataque feroz de los mismos y del mundo que estos describen.

\section{Resementización de Macbeth y Lady Macbeth}

A pesar de la conciencia del mal que se desprende de la obra y de Macbeth, paradójicamente el público empatiza con este personaje. Queda la duda de si Macbeth es malo por naturaleza, o bien es un ser condenado a la maldad, tal vez por falta de coraje: «is he strong and courageous, or weak and cowardly? Is he noble but corrupted, or evil from the start?» (Clark y Mason 2015, 103). El gran logro de Shakespeare es hacer que el público, siendo consciente de su maldad, siga percibiéndolo como héroe, que batalla hasta el final con dignidad contra Macduff, incluso después de ver ante sus ojos que se hacen realidad las profecías sobrenaturales que confirman su derrota:

Aunque el bosque de Birnam haya venido a Dunsinane y estés tú frente a mí, tú, que no has nacido de mujer, lucharé hasta el final (Macbeth, V.vii, 343-345).

En buena medida, esta tensión entre creerle un criminal y empatizar con él se basa en la presentación de las acciones de Macbeth como resultado de fuerzas que él no controla ni puede evitar (el Gran Mecanismo), pero a la vez en la sospecha de que hay connivencia por su parte. Así, el público se identifica con el personaje porque nos damos cuenta de que pasa por dificultades como las de cualquiera: «is in an odd sense, 'one of us'» (Goldman 1985, 110). Como Macbeth, condenado por el Gran Mecanismo, también nosotros nos sentimos a menudo tentados y sucumbimos a hacer el mal. 
Dado el marco de resematización, la maldad de Macbeth en M.B.I.G. se puede interpretar como resultado del absurdo sistema empresarial de la sociedad posindustrial y posmoderna: él actúa como lo hace a causa de las presiones empresariales de su puesto. Paralelamente, se resemantiza la empatía del público con el personaje, cuando entendemos que lo que a él le pasa es lo que a nosotros en nuestros trabajos. Así, M.B.I.G. no ataca tanto al personaje, como al espantoso sistema de competencia que le/nos obliga a actuar con crueldad para sobrevivir dentro del capitalismo y/o el lugar de trabajo.

Junto a Macbeth, es preciso remitirse al otro personaje clave de la obra de Shakespeare: Lady Macbeth. Y es que la tragedia de Macbeth se basa en gran medida en ella, como incitadora de las acciones y catalizadora de la maldad:

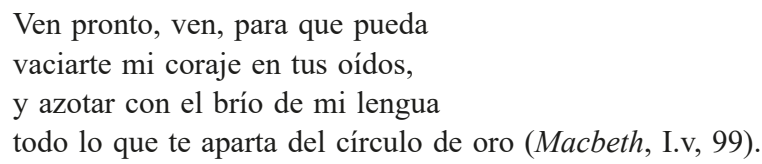

En este sentido, es memorable el pasaje en que ella renuncia a su sexualidad/ maternidad, solo para incitar a Macbeth e incitarse a sí misma a cometer todos los crímenes precisos:

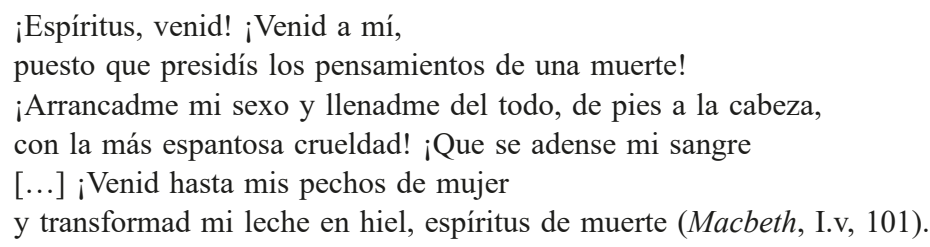

La resemantización de esto la apunta ya Paco Tomás en el prólogo de M.B.I.G., con una interpretación de Lady Macbeth como «femme fatale» que es, claramente, posromántica, $\mathrm{y}$, en particular, bastante actual, por el lenguaje empleado para describirla (por cierto, no poco machista): «Una mujer que ambiciona desde el coño y atrapa desde una fuente de placer que nunca lo será de vida» (cfr. Martret 2014, 14). Por su parte, en relación con el marco posmoderno, Martret, en una acotación, hace aparecer a Lady Macbeth «con un aire de Ava Gardner en los años 60» (M.B.I.G., II.i, 40). O sea, Lady Macbeth es una femme fatale al estilo vintage que se respira en toda la obra, en la estela de Mad Men. Pero no se trata solo de que Lady Macbeth esté traspuesta en M.B.I.G. meramente como elemento estético posmoderno, sino que con frecuencia a través de ella se produce la resemantización de Macbeth.

En uno de los casos de mayor carga irónica, Camelia dice que «la presencia de mujeres es una característica habitual en las empresas altamente cualificadas como la nuestra. Las mujeres, en los equipos directivos, favorecen la consolidación empresarial» (M.B.I.G., I.i, 19). A todas luces, esto no se corres- 
ponde con lo que se ve en la obra. Por un lado, a pesar de ser ella misma una mujer inteligente, no forma parte del equipo directivo, sino que es una secretaria, y su único papel es el de guía del público, es decir, un papel servicial, como serviciales son los roles que asume al interferir en Macbeth. Por otro, Macbeth, que es la realidad de la empresa en que ella trabaja, muestra que en el equipo directivo no hay ninguna mujer. Y es que Lady Macbeth, aun siendo la incitadora de su marido, tampoco forma parte del grupo de poder. La ironía, pues, está en dos aspectos que desmienten a Camelia: ni el efecto de la mujer es beneficioso, porque lo que Lady Macbeth consigue es una conjuración plagada de muerte, ni es verdad que haya mujeres en la dirección de la empresa, lo que se hace eco del problema del techo de cristal en las sociedades actuales, divulgado ampliamente por los periódicos (Sahuquillo 2012). Resemantizando Macbeth, por tanto, lo que Martret plantea es el carácter patriarcal de la organización empresarial del capitalismo en la sociedad posmoderna.

\section{RESEMANTIZACIÓN DE LO SOBRENATURAL: LAS BRUJAS}

El papel de las brujas en la obra de Shakespeare es esencial. Ellas son el resorte que hace arrancar el engranaje del mecanismo absurdo y de la ironía trágica: la profecía que en principio parece positiva se troca en maldición. Ese es el sentido de sus enigmáticas palabras: «Lo bello es feo y feo lo que es bello» (Macbeth, I.i, 57). Así, la tragedia «no es sino resultado del primer encuentro con la tentación» (Conejero Dionís-Bayer 2015, 11). Es decir, las brujas, en línea con lo que decía Kott, no funcionan a la manera de los dioses de la tragedia clásica, sino que son una alegoría de la tentación $\mathrm{y}$, con la forma del típico deus ex machina, catalizan el absurdo del Gran Mecanismo. Macbeth es, así, víctima de ese mecanismo, y por eso empatizamos con él, porque, como él, también nosotros podemos llegar a condenarnos. Este sentido alegórico y su función catalizadora de las brujas también se resemantizan en M.B.I.G.

En la obra de Martret, las brujas son administrativas de la empresa. Se las retrata siguiendo la moda vintage del resto de la obra y con referencias parecidas a productos culturales posmodernos, en particular David Lynch. En efecto, en una acotación, Martret señala que «parecen salidas de una película de David Lynch. De unos cuarenta y cinco años, con pelo corto y cardado, la tez muy pálida, los labios pintados de rojo, vestidas con unos trajes chaqueta que nos recuerda la moda de los años 60 y con bolsos y zapatos de tacón a juego» (M.B.I.G., I.ii, 21).

Martret, en esa misma acotación, señala que, al empezar la obra, las brujas ya están en escena: «Miran al público mientras este entra. Están serias, serenas. Cuando todo el público ha ocupado su lugar y ya han pasado unos segundos, comienzan a hablar» (M.B.I.G., I.ii, 21). Martret persigue provocar una sensación de incomodidad. Dado que, al entrar, todo le indica al público que está en 
una empresa de los años 60, en principio esa incomodidad ha de basarse en su condición de secretarias, que es lo que a primera vista parecen. Y es posible suponer que esta sensación de incomodad se apoye en la idea, tan extendida en el imaginario colectivo, de que los trabajadores del ámbito de la administración desempeñan sus funciones con dejadez, de manera problemática, incluso desagradable, especialmente en el sector público (el tópico del funcionario). Es verdad que, en cuanto empiezan a hablar, queda claro que se trata de las brujas de Macbeth, pero entonces la incomodidad primera da paso al retrato satírico. Y es que así se consigue suscitar la asociación de ideas humorística: es normal que las secretarias sean unas brujas, por decirlo parafraseando la expresión coloquial que se suele usar para definir el difícil trato normalmente atribuido a este tipo de trabajadoras administrativas.

Como se ve, el significado del mundo empresarial y laboral queda perfectamente combinado con el original: las secretarias como brujas. Gracias a este paralelismo, es posible una trasposición en el significado de las palabras de las brujas de Shakespeare. En Macbeth, siguiendo la trascripción, prácticamente igual, de M.B.I.G. (aunque con una bruja menos), tiene lugar este diálogo:

\section{BRUJA 2: ¿Qué has hecho, hermana?}

BRUJA 1: Matar cerdos.

BRUJA 2: ¿Dónde?

BRUja 1: La mujer de un marinero tenía castañas en su falda, y una tras otra las cogía y las roía, roía, roía. «Dame una», le digo. «Atrás, so Bruja», me grita la asquerosa... que además tenía un culo enorme. Su marido se fue a Alepo, es el patrón del Tigre. Pues yo ya sé lo que haré, como una rata sin cola, navegaré hasta ese buque sobre una tela de cedazo... Lo haré, lo haré, lo haré.

Bruja 2: Pues yo haré soplar el viento para ti (M.B.I.G., I.iv, 25-26).

La conversación continúa hasta que llega Macbeth. En la obra de Shakespeare, tiene el sentido de mostrar el aspecto sobrenatural de las brujas, porque se está tramando un maleficio contra «la mujer de un marinero» por un desaire a una de ellas. Esto sirve de apoyo a la ironía trágica: se advierte al público de que la posterior profecía a Macbeth, aunque aparentemente le predice un futuro bueno, se trata de algo malo. Ahora bien, en el marco de resemantización de M.B.I.G., no es aventurado suponer una interpretación propia de la sociedad posindustrial.

Por un lado, las brujas, como administrativas, parece que estuvieran realizando una de estas conversaciones intrascendentales sobre vidas ajenas, que se les suele achacar en el imaginario colectivo. Y ello, mientras desatienden sus funciones laborales, toda vez que esta conversación tiene lugar en mitad del despacho, donde se supone que deberían estar trabajando. Por otra parte, es preciso recordar que, en M.B.I.G., no son tres, sino dos brujas, y no aparece Hécate, que, en la mitología griega, era la reina de todas ellas. Esto puede deberse a la necesidad de reducir el número de actores, para, a su vez, reducir 
costes. Pero también puede expresar los problemas de personal en las empresas, como símbolo de despido laboral, especialmente teniendo en cuenta que el público familiarizado con Macbeth se ha de dar cuenta de esta reducción de personal. Así, puede interpretarse que las brujas, como administrativas, están desatendiendo sus funciones laborales, con una conversación de cotilleo, a causa de la frustración que típicamente se produce cuando, al despedir a una compañera, se tienen que asumir nuevas labores. Nótese que, en la propia estructura de M.B.I.G., el texto de la bruja suprimida es repartido en el diálogo de las dos brujas que se mantienen. Desde este punto de vista, la supresión de Hécate puede tomarse, a su vez, como el despido de la jefa o coordinadora del departamento de administración, en ese tipo de situaciones laborales en las cuales los trabajadores subalternos que mantienen el puesto de trabajo deben asumir las labores de coordinación, sin aumento de sueldo o reconocimiento en la categoría. Si se acepta esta interpretación, entonces al sentido original de las brujas en Macbeth como deus ex machina y alegoría de la tentación que desata la tragedia puede añadírsele otro sentido alegórico en M.B.I.G.: el de la venganza. Las brujas, como administrativas, tentarían a Macbeth para vengarse del trato recibido en la empresa. Más que una profecía, se trataría del tipo de comentarios maledicentes que siembran la cizaña en el ambiente de trabajo y derivan en un proceso de remodelación, duro para la dirección de la empresa (Duncan suprimido como presidente por Macbeth, que no es capaz de mantenerse como directivo y es sustituido por Macduff), pero sin consecuencias para la plantilla de administración, que mira con indiferencia el caos, a pesar de haber sido causante de ello. Esta interpretación como venganza laboral se sustenta en el propio texto. $\mathrm{Y}$ es que, como ya se ha señalado, la profecía a Macbeth la hacen las brujas después de la conversación en que habían hablado sobra una venganza contra «la mujer de un marinero» por un desaire.

Sustentan esta interpretación otros aspectos relacionados con la puesta en escena, que también aceptan una resemantización en la misma línea. Desde muy pronto, uno de los problemas a que se enfrentó Macbeth fue el de «la representación de lo sobrenatural» en el escenario. Por ejemplo: «en la historia y el folklore europeo las brujas han sido siempre mujeres viejas, pero puesto que aquí representan principalmente la seducción y la atracción al mal, la vejez quizá les restaría credibilidad, sobre todo por cómo dar vida a las brujas y demás elementos sobrenaturales». Además: «en tiempos de Shakespeare y durante el siglo XVII esos papeles fueron siempre interpretados por hombres» (Portillo 2007, 176). Esto explicaría el carácter entre femenino y masculino que se les da en la obra original, cuando las interroga Banquo al encontrarse con ellas: «podríais ser mujeres; / vuestras barbas me impiden, sin embargo, creer / que lo sois» (Macbeth, I.iii, 75). Un problema parecido, pero multiplicado, se presenta en M.B.I.G.: no es solo cómo hacer que estos elementos sobrenaturales se representen en escena, sino hacerlo de manera apropiada como parte de una historia de empresa posmoderna. 
Las brujas de M.B.I.G., según son descritas en una acotación citada más arriba, tienen unos cuarenta y cinco años y visten a la manera de los 60; en particular, el vestuario se parece al de Mad Men, como se puede ver comparando las figuras 5 y 6 (abajo). De este modo, se consigue un punto intermedio entre la visión tradicional de vejez y la juventud y seducción necesarias para encarnar la tentación. Además, es una edad crítica, porque, en caso de despido, es difícil encontrar trabajo, lo que refuerza la hipótesis anterior de que, a través de las brujas, se ofrece el punto de vista vengativo de unas trabajadoras que han sufrido un reajuste de plantilla en la empresa.

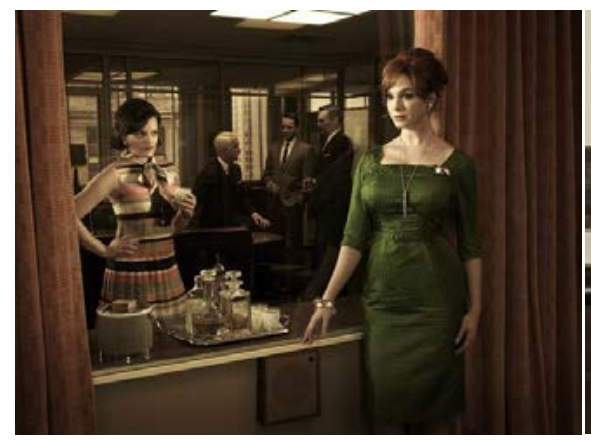

Figura 5. Personajes de Mad Men

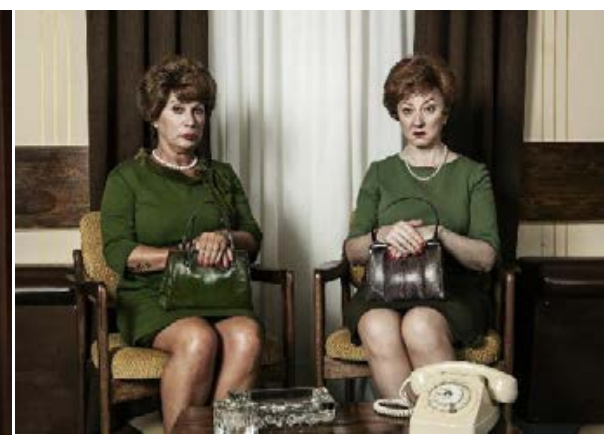

Figura 6. Las brujas de M.B.I.G.

Por lo que se refiere a otros elementos sobrenaturales, la obra de Shakespeare comienza con «Truenos y relámpagos» (Macbeth, I.i, 55), como ambientación propia de las brujas. Martret lo sustituye por: «Sonido de lluvia tras los cristales» y sonido de «máquinas de escribir». Además, añade un elemento más: «Mesita con botellas de cristal, que contienen alcohol, y vasos» (M.B.I.G., I.ii, 20). Como el resto del decorado de La Pensión de las Pulgas, esto está inspirado en la estética de los años $60 \mathrm{y}$, en particular, Mad Men. Compárense la semejanza del minibar en el salón presidencial de La Pensión de las Pulgas (Fig. 3), con la imagen de Mad Men de la figura 5.

Dado que La Pensión de las Pulgas para M.B.I.G. era un espacio cuidado estéticamente con todo lujo de detalles, el hecho de que la lluvia, la máquina de escribir y el minibar sean los únicos recogidos en la acotación del texto publicado indica que no son meramente decorativos y han de tener una función particular. Las botellas y vasos de alcohol permiten establecer un paralelismo entre el mundo de la empresa, en el que funcionan como minibar, y el mundo de Macbeth, en el que significan las pócimas que suelen asociarse a la brujería. De manera parecida, se resemantizan los truenos y relámpagos originales como elementos propios de alienación laboral, en forma de sonidos de lluvia y máquinas de escribir. Así, esta adaptación de lo sobrenatural refuerza la interpretación de las brujas/administrativas que se vengan por sus condiciones de tra- 
bajo. A su vez, esto contribuye a la ironía trágica, porque se desmienten como negativas las bondades de la empresa que Camelia pretende demostrar en sus intervenciones.

\section{RESEMANTIZACIÓN DEL ESPACIO}

En el apartado anterior, se han analizado algunos aspectos asociados al espacio, como el decorado y el vestuario, por su relación con lo sobrenatural. Por lo que atañe a la estructuración misma del espacio, cabe estudiar ciertos procesos de resemantización.

García Barrientos habla del valor de la estructura espacial, más allá de la mera descripción técnica. En La casa de Bernarda Alba: «La relación sintagmática entre los tres decorados de la obra podría tener el sentido de un repliegue hacia el interior de la casa, cada vez más lejos del exterior, de la calle» (García Barrientos 2008, 132). El espacio refuerza el sentido de represión de Bernarda Alba sobre sus hijas, encerradas dentro de la casa y, dentro de esta, cada vez más recluidas en habitaciones más interiores.

Como obra de teatro, por así decir, convencional, Macbeth se representa sobre un único escenario (espacio real), que significa distintos lugares de la ficción (espacios dramáticos). Aceptada esta convención, en Macbeth, como en La casa de Bernarda Alba, los cambios en los espacios dramáticos siguen la lógica de repliegue del exterior al interior. La obra comienza a la intemperie del campo de batalla, donde se produce el encuentro con las brujas, y termina en las habitaciones privadas de Macbeth, en su castillo. En ese movimiento hacia al interior, la escena del banquete es capital, tanto en la trama (Macbeth, ante la visión de Banquo, empieza a perder el control de la situación y comienza su periplo hacia la muerte), como en el espacio (este punto de inflexión en la trama se produce en un salón de eventos, a medio camino entre el exterior del campo de batalla y los aposentos privados de Macbeth).

Aunque Macbeth pretende ser lo que pasa realmente en la empresa, lo cierto es que se representa casi al completo en M.B.I.G. y, por tanto, la acción también pasa por el proceso de repliegue del exterior al interior. La diferencia es que esto no ocurre en un escenario convencional. M.B.I.G., como obra de teatro inmersivo, quiere hacernos creer que no hay convención representacional, o sea, que La Pensión de las Pulgas es realmente el espacio de la acción dramática, o, por mejor decir, que contiene todos los espacios por los que transcurre la acción dramática.

Por supuesto, esto no es más que un truco ilusionista. En última instancia, en el teatro inmersivo también opera la convención teatral. En La Pensión de las Pulgas, a pesar del gran efecto ilusionista conseguido con la lograda reforma de una vivienda habitual, un mismo espacio real significa varios espacios dramáticos, como en cualquier obra de teatro. A diferencia de lo que se preten- 
de hacer creer con la ilusión inmersiva, el despacho presidencial de la empresa no es solo tal despacho, porque ahí ocurren acciones que se desarrollan en diferentes espacios dramáticos. Por ejemplo, en el despacho se representa la conversación del rey Duncan con Malcolm, sobre Macbeth (M.B.I.G., I.iii, 2224), así como la conversación de Macbeth con Banquo y su encuentro con las brujas, que en teoría está pasando a cientos de kilómetros (M.B.I.G., I.iv, 2529). Asimismo, los aposentos de Macbeth representan indistintamente diferentes estancias de su castillo.

Con todo, la estructura espacial de M.B.I.G. refuerza la sensación de movimiento al interior. Por un lado, de entre todos los espacios dramáticos que Martret podría haber decidido hacer reales en La Pensión de las Pulgas, elige, precisamente, los tres más importantes en el proceso de repliegue del exterior al interior: el despacho/salón de la corte, la sala del banquete y los aposentos de Macbeth. Por otro, la ilusión de que La Pensión de las Pulgas es el espacio real de la acción dramática le permite al espectador vivir ese repliegue. O sea, gracias al decorado y al hacer que el público vaya cambiando de espacio según avanza la trama, se consigue la ilusión de que realmente estos espacios son lo que parecen ser. Y, al elegir precisamente estos tres espacios, que representan muy bien el movimiento hacia el interior, el público experimenta físicamente este repliegue. Ya no es solo que empaticemos con el protagonista porque tenemos la sensación de que su desgracia podría ser la nuestra, sino que vivimos esa desgracia porque literalmente nos hundimos en ella a través del espacio. De este modo, se consolida la resemantización que se viene señalando, porque, al vivir ese hundimiento en nuestro presente, lo relacionamos más naturalmente con el mundo empresarial que describe Camelia y que está más cerca de nuestro presente, y no tanto con el mundo de nobles de Macbeth.

\section{Conclusión: M.B.I.G., COMO MAD BETH}

En el teatro off de los últimos años, los proyectos teatrales de La Casa de la Portera y La Pensión de las Pulgas se cuentan entre los más sobresalientes. Con el diseño escenográfico de Alberto Puraenvidia, José Martret pone en escena Ivan-OFF, a partir de Ivanov de Chejov, y M.B.I.G. (McBeth International Group), a partir de Macbeth, de Shakespeare, en un formato de teatro site-specific e inmersivo, que se inserta en una tendencia de renovación teatral dentro y fuera de España, desde Microteatro por Dinero, hasta Sleep No More, que es precisamente una adaptación inmersiva de Macbeth. Por eso, es relevante el estudio de obras como M.B.I.G., y de hecho ya ha recibido la atención de la crítica académica, como Ruiz Lluch (2017). Yo mismo he realizado en otro lado un estudio de M.B.I.G., reivindicando que no es meramente una adaptación de Macbeth, sino una obra nueva, con argumentos de la semiótica teatral y de la teoría de la hipertextualidad de Genette (Laín Corona 2017). Para completar 
esta hipótesis, aquí se ha analizado el sentido que adquiere Macbeth dentro de M.B.I.G.

Atendiendo a su naturaleza teatral y a su estética, se ha señalado que M.B.I.G., como en general el teatro inmersivo, es una nueva vuelta de tuerca en lo que Lehmann llama teatro posdramático, es decir, aquel que desde los años 60 busca romper con la tiranía del texto para imponer la experiencia del teatro como espectáculo. Se ha argumentado que esto, aunque inserto en la tradición del arte y la literatura posmodernista, también tiene que ver con la posmodernidad. Y es que la exaltación de lo sensible $\mathrm{y}$, particularmente, lo visual es una de las características de la sociedad De la ligereza, que describe Gilles Lipovetsky en el ensayo que lleva ese título. En particular, M.B.I.G. hace uso de elementos estéticos propios de los productos culturales de masa. Por un lado, se ha llamado la atención sobre el hecho de que Macbeth es en la actualidad objeto del fandom, por lo que su uso para M.B.I.G. responde en gran medida a este fenómeno tan característico de la posmodernidad. Y, por otro, se construye como un pastiche de estéticas pasadas, imitando, a su vez, aspectos de la serie de televisión Mad Men.

A pesar de ello, se ha explicado que la posmodernidad no tiene que ser algo negativo. La propia serie de televisión de Mad Men, aun siendo pastiche, es un inteligente ataque al consumismo de las sociedades occidentales. Por lo que respecta a M.B.I.G., está lejos de ser el tipo de subproducto cultural que el fandom suele hacer con Macbeth, como trajes de Halloween o memes, sino que es una crítica del capitalismo posindustrial, en lo que tiene que ver con el funcionamiento empresarial y sus efectos negativos sobre las dinámicas laborales y sobre la vida personal de los trabajadores.

Para llegar a ello, no hay indicios en el texto de M.B.I.G. de que Martret partiera del libro Shakespeare en la empresa, de Normal Augustine y Kenneth Adelman, aunque es una relación interesante, porque aquí se hace una interpretación de la producción teatral shakespeariana que sirve de guía para el éxito empresarial. En cambio, sí hay referencias en M.B.I.G. a otros manuales de este tipo, que son, por lo demás, propios de la sociedad psi posmoderna, como Los siete hábitos de las personas altamente efectivas, de Covey.

Para su particular aplicación de Macbeth al mundo de la empresa, Martret pone en práctica una serie de estrategias de resemantización. Ante todo, está la estructura metateatral e interactiva: M.B.I.G. es una empresa de prestigio de los años 60, a la que los espectadores asisten como invitados para ver las claves de su éxito, y Macbeth se representa como si fuera lo que pasa en esa empresa. Dentro de este marco, es inevitable interpretar los hechos de Macbeth de manera diferente a la original, como si la trama de ascenso al poder fuera una representación de los problemas de una empresa.

Ahora bien, en ningún momento se plantea que Macbeth sea una representación, por así decir, simbólica, sino que, dentro de la ilusión inmersiva de M.B.I.G., se hace creer que es realmente lo que pasa en esa empresa. Para ello, 
es clave el personaje de Camelia. Como es la encargada de guiar a los espectadores por la empresa, se dirige a ellos en varios monólogos; así, en sus palabras, se da por sentado que el rey Duncan no es el rey Duncan como tal, sino realmente el presidente de la empresa. Asimismo, las palabras de Camelia sirven para resemantizar los diálogos de Macbeth, a partir de ciertos paralelismos. Por ejemplo, tanto Macbeth como Camelia usan la palabra luchar: Macbeth lo hace porque acaba de terminar una batalla en una guerra, pero puede interpretarse como una acción de conflicto laboral, toda vez que Camelia la ha usado antes con ese sentido. De manera parecida, Camelia, que es un personaje de M.B.I.G., se infiltra en Macbeth desempeñando funciones paralelas: ella es secretaria en la empresa, pero interactúa con los personajes de Shakespeare con roles similares de lacayo, emisario, etc. Su presencia, propia del mundo empresarial, en Macbeth refuerza la interpretación resemantizada de esta obra. Desde este punto de vista, son especialmente relevantes los casos en que esta infiltración se hace con apoyo de objetos del decorado, como un interfono o un teléfono.

Teniendo en cuenta este proceso de resemantización, se han propuesto interpretaciones de varias escenas, personajes y espacios. Las brujas y elementos sobrenaturales representan los problemas derivados de los ajustes de las plantillas en una empresa, siendo bastante significativos algunos paralelismos, como hacer que los truenos y relámpagos de Shakespeare aparezcan como sonidos de máquinas de escribir, de modo que lo sobrenatural se convierte en M.B.I.G. en un fenómeno de alienación laboral.

Partiendo del análisis de estas escenas y personajes, se ha ofrecido una interpretación general de M.B.I.G. como tragedia. Según Jan Kott, en Shakespeare, la tragedia se basa en la existencia de un mecanismo absurdo en que los seres humanos estamos condenados a matar para sobrevivir, o morir. En Macbeth, ese mecanismo se aplica a la búsqueda de poder, y en ella el mal se percibe de manera empática porque nos damos cuenta de que los crímenes de Macbeth tal vez los podríamos cometer nosotros, si estuviéramos sometidos a la misma tentación. En M.B.I.G., el mecanismo deja de ser una plataforma para la búsqueda de poder, al menos en un sentido medieval, y se convierte en la lógica de funcionamiento de una empresa. De este modo, lo que se expresa es que estamos atrapados en el engranaje de la lógica capitalista, condenados a cometer acciones atroces para sobrevivir en el duro ambiente de competencia que se genera en las empresas, o dejarse pisar. Por eso, la empatía con el mal también se resemantiza: queda la impresión de que los problemas de Macbeth en su empresa son los mismos que los nuestros en nuestra vida laboral diaria y que, por tanto, las atrocidades que él se ve absurdamente obligado a cometer podríamos llegar a cometerlas nosotros.

Como se ve, M.B.I.G., partiendo de Macbeth, es un retrato muy crítico del capitalismo y, en particular, del mundo empresarial y las relaciones laborales, pero ajustado dentro del marco de la posmodernidad en que funciona la misma 
lógica capitalista. Eso mismo había hecho antes Mad Men, al valerse de la estética posmoderna para criticar el problema del consumismo, que es tan propio de la posmodernidad. Con estos dos referentes, por tanto, M.B.I.G. es, de algún modo, una suerte de Mad Beth.

\section{BIBLIOGRAFÍA CITADA}

Aguilar, Andrea. 2012. «Un macabro hotel inquieta a Nueva York». El País, 8 de marzo. Acceso el 20 de enero de 2017. http://cultura.elpais.com/cultura/2012/03/07/actualidad/ 1331129178 768422.html

Aristóteles. 2002. Poética, prólogo, traducción y notas de Antonio López Eire y epílogo de James J. Murphy. Madrid: Istmo.

Augustine, Norman y Kenneth Adelman. 2000. Shakespeare en la empresa. La guia del Bardo de Stratford para liderar y triunfar en el escenario de la empresa, trad. Alejandro Pareja Rodríguez. Madrid: Edaf.

Bauman, Zygmunt. 2003. Modernidad líquida, trad. Mirta Rosenberg en colaboración con Jaime Arrambide Squirru. México: Fondo de Cultura Económica.

Booker, M. Keith y Bob Batchelor. 2016. Mad Men. A Cultural History. London: Rowman \& Littlefield.

Clark, Sandra y Pamela Mason. 2015. «Introduction». En William Shakespeare, Macbeth, ed. Sandra Clark y Pamela Mason, 1-124. London: Bloomsbury Arden Shakespeare.

Conejero Dionís-Bayer, Manuel Ángel. 2015. «Introducción». En William Shakespeare, Macbeth, ed. bilingüe del Instituto Shakespeare dirigida por Manuel Ángel Conejero Dionís-Bayer, 9-49. Madrid: Cátedra.

Goldman, Michael. 1985. Acting and Action in Shakespearean Tragedy. Princeton: Princeton University Press.

García Barrientos, José Luis. 2008. Cómo se comenta una obra de teatro. Madrid: Síntesis.

Jameson, Fredric. 1996. Teoría de la postmodernidad, trad. Celia Montolío Nicholson y Ramón del Castillo. Madrid: Trotta.

Kott, Jan. 1967. Shakespeare Our Contemporary. London: Routledge.

Laín Corona, Guillermo. 2017. «M.B.I.G. (Mcbeth Internacional Group), de José Martret: Transposición metateatral de Macbeth, de Shakespeare». En Teatro como espejo del teatro, ed. Urszula Aszyk, José Romera Castillo, Karolina Kumor y Kamil Seruga, 251267. Madrid: Verbum.

Lehmann, Hans-Thies. 2006. Postdramatic theatre, trad. Karen Jürs-Munby. London: Routledge.

Lipovetsky, Gilles. 2000. La era del vacío. Ensayos sobre el individualismo contemporáneo, trad. Joan Vinyoli y Michèle Pendanx. Barcelona: Anagrama.

Lipovetsky, Gilles. 2016. De la ligereza. Hacia una civilización de lo ligero, trad. Antonio-Prometeo Moya. Barcelona: Anagrama.

López de Arriba Escribano, Luis. 2017. «Nuevos formatos teatrales. Microteatro y teatro en serie, abriendo caminos». Don Galán 7. Accesible en: http://teatro.es/contenidos/ donGalan/donGalanNum7/pagina.php?vol=7\&doc=1_7\&pag=1

Lozano, Javier, y Alberto Hermida. 2007. «Macbeth: culturas populares y 'fandom'». Comunicación: Revista Internacional de Comunicación Audiovisual, Publicidad y Estudios Culturales 5: 315-332. Accesible en: http://www.revistacomunicacion.org/pdf/n5/ articulos/macbeth_culturas_populares_y_fandom.pdf 
Mandell, Jonathan. 2015. «Discovering The Theatre: Lessons of The Fall Season from A Class Of New York Newcomers». HowlRound. A knowledge commons by and for the theatre community, 22 de diciembre. Accesible en: http://howlround.com/discoveringthe-theatre-lessons-of-the-fall-season-from-a-class-of-new-york-newcomers (consultada: 20-01-2017)

Martret, José. 2014. M.B.I.G. (McBeth International Group). Madrid: Bartleby Editores.

Nimo, Ana M. ${ }^{a}$ 2015. «El Microteatro se hace grande». El Mundo, 3 de octubre. Acceso el 21 de septiembre de 2017 http://www.elmundo.es/madrid/2015/10/03/560cf4c8ca 4741d02a8b4570.html

Pearson, Mike. 2010. Site-Specific Performance. London: Palgrave MacMillan.

Portillo, Rafael. 2007. «La singularidad literaria y escénica de Macbeth». Comunicación: Revista Internacional de Comunicación Audiovisual, Publicidad y Estudios Culturales 5: 173-186. Accesible en: http://www.revistacomunicacion.org/pdf/n5/articulos/la_singularidad_ literaria_y_escenica_de_macbeth.pdf

RAE. 2009. Nueva gramática de la lengua española. 2 vols. Madrid: Espasa.

Romera Castillo, José, ed. 2011. El teatro breve en los inicios del siglo XXI. Madrid: Visor Libros.

Romo, José Luis. 2016. «La última función de La pensión de las pulgas». El Mundo, 26 de julio.

Ruiz Lluch, María Reina. 2017. «M.B.I.G. (McBeth International Group) de José Martret: un Macbeth cuerpo a cuerpo en La Pensión de las Pulgas». En El teatro como documento artístico, histórico y cultural en los inicios del siglo XXI, ed. José Romera Castillo, 251-267. Madrid: Verbum.

Sahuquillo, María R. 2012. «Un muro de corbatas ante la mujer directiva». El País, 11 de abril. Acceso el 31 de enero de 2017. http://sociedad.elpais.com/sociedad/2012/04/11/ actualidad/1334167079_033078.html

Shakespeare, William. 2015. Macbeth, ed. bilingüe del Instituto Shakespeare dirigida por Manuel Ángel Conejero Dionís-Bayer. Madrid: Cátedra.

White, Gareth. 2012. «On Immersive Theatre». Theatre Research International 37 (3): 221 235. https://doi.org/10.1017/S0307883312000880

Fecha de recepción: 20 de noviembre de 2017.

Fecha de aceptación: 15 de marzo de 2018. 